This is an electronic reprint of the original article. This reprint may differ from the original in pagination and typographic detail.

Please cite the original version: A. Puisto, A. Sievers, L. Ranta, T. Marstio, A. Guilland (2018) Creating Insights to Working Life Requirements Among Students in HEI, ICERI2018 Proceedings, pp. 8290-8297.

doi: $10.21125 /$ iceri.2018.0505 


\title{
CREATING INSIGHTS TO WORKING LIFE REQUIREMENTS AMONG STUDENTS IN HEI
}

\author{
Puisto, A ${ }^{1}$, Sievers, A. ${ }^{1}$, Ranta, L. ${ }^{1}$, Marstio, T. ${ }^{1}$ \& Guilland, A. ${ }^{1}$ \\ ${ }^{11}$ Laurea University of Applied Sciences, (Finland)
}

\begin{abstract}
In 2016, nearly 1.3 million young people in the EU were out of work and actively sought for 12 months or more for work. Lack of education and work experience were the main driving factors in increasing the likelihood of long-term unemployment. Educational attainment strongly influences labor market participation. One out of two European graduates remained however worried about their career. Moreover, with time some gave up hope of being employed in their field. At the same time, around $38 \%$ of the EU companies experienced difficulties in finding suitable candidates. Various reasons could be behind this so-called skill mismatch.
\end{abstract}

According to various studies graduates have insufficient understanding of the required competencies and are unfamiliar with the world of work. They often lack self-awareness of the skills they have and how they correspond working life requirements. Many students consider that education should assure the development of the working life skills and they neglect their role in the personal and professional enhancement process.

This paper discusses a study where the focus was in creating an understanding of recruitment criteria among higher education (HEI) students. The sample consisted of 26 employers. Thirty-two health-care and seven business administration students planned and realized the fieldwork through audiorecorded qualitative interviews and participated in the analysis of the results. The results were in line with previous studies which underlined the importance of the entrepreneurial skills both among business and health-care sector. Some differences appeared in the set of skills required in these two different cases.

The study proved out to be an excellent way to create the understanding of the requirements among students who also found the learning method very interesting. Aside from creating deep insight into employers' expectations, students learned about the various existing options they have when they plan their future career. The study opened views to the specificities of different working environments, and the skills needed to assure future recruitment. If you want to work in a particular work environment (such as a nurse in the business world), you need to work hard to attain the level of skills and competencies required for accomplishing your tasks. The requirements are not similar in every job and work environment. To succeed in building your career path and developing the needed qualities, you have to maintain self-control and have a goal-oriented approach.

It seems justified to claim that students should at an early phase of their educational path learn to understand employment requirements. They should also take clear responsibility for their learning process to assure obtainment the competencies needed for future professional and private life. The students' development process requires support from both working world and education. There is a need for dialogue between employers, educators, and students. Open, up-to-date and continuous interaction and communication between the stakeholders is needed to diminish the skills mismatch and answer to the changing requirements of working life.

Keywords: Skill mismatch, entrepreneurial skills, transversal competences, job requirements, career development, training, learning

\section{INTRODUCTION}

Modern societies challenge business, employers and job-seekers in many ways. Globalisation and development of logistics created a new world of work. Especially digitalisation, automatization, and robotization creates challenges. The development of digital technology and logistics has promoted globalization and modernization, created an increasingly interconnected world and given rise to the knowledge societies. Individuals need to master various technologies and to continuously select between and make sense of large amounts of information. The competences that individuals need to display have become more complex, requiring more than mastering of specific limited skills. 
For young students, the working world is often wholly or partially unknown. Many have not had an active role in business or other chances of getting a deep understanding of the challenges before starting their studies. Therefore, their focus is often on obtaining an official diploma and relying on the power of the document as a key to employment. After graduation these young people realize that to stand out among the job applicants it is not enough to get good grades, deliver good papers and get a reasonable degree. As one employer we interviewed during our study project expressed it plainly: "The substance matter knowledge learned at the university we take for granted. So that is not enough - the job seeker stands out with the employability skills."

We know little about the employability requirements of future working life although various studies concentrate on building pictures of it. The technological revolution is continuous, and much of the technology that will be used in the future is not yet available. It seems however clear that for both social and working life people need various skills or competences.

Skills are described, on the one hand, as human characteristics which can develop through education, training, and experience, although individual traits play an important role in promoting some skills [1]. On the other hand, skills can be described as "generalizable attributes of individuals that confer an advantage in the labor market" [2]. Competences are broader than knowledge and skills [3] and focus on what the people can do rather than what they know. Competences can be interpreted instead as behavioral manifestations of talent" [4] or "observable aspects of performance in particular circumstances" [5]. Competences are not personal constructs or traits but rather dispositions that can be attributed to individuals, teams, and organizations. They are hidden attributes identified and defined in a community of practice and structured around demands and tasks [4].

Competences are not innate, inborn characteristics, instead they are learned. Learning competences is an on-going, lifelong, learning process which occurs in multiple settings. "The main settings and social institutions relevant for the development of competencies besides school are families, peers, work, political life, religious life, cultural life" [3].

The so-called transferable (generic/soft/employment) competences can be transferred from one job or social setting to another [1]. They can be learned within an educational or a social context and then transferred to a career, and generally, be used and developed in all areas of people's life. Transversal competences include digital skills, learning skills, social and civic skills, sense of initiative and entrepreneurship, and cultural awareness and expression.

Bacigalupo, Kampylis, Punie \& Van den Brande [6] describe the competences required in working life as horizontal and entrepreneurial management of the various domains applicable to all areas of life. They define entrepreneurship as acting upon opportunities and ideas and transforming them into value for others. The value created through entrepreneurial action can be financial, cultural, or social. The respective competences can be considered, e.g., as internal entrepreneurship or social entrepreneurship. These consist of both personal qualities, different skills, and actions which create value in private, public and third sectors or any hybrid combination of the three. Entrepreneurship applies to all spheres of life and facilitates citizens' personal development, to active contribution to social development, entrance the job market, self-employment, or to start-up ventures of cultural, social or commercial motive [5].

The conceptual entrepreneurship EntreComp model consists of 15 different competences or building blocks as presented in Figure 1 [6]. These competences are divided into three groups: 1) Into action: taking the initiative, planning \& management, coping with ambiguity, uncertainty \& risk, working with others, learning from experience 2) Resources: self-awareness \& self-efficacy, motivation \& perseverance, mobilizing resources, financial \& economic literacy, mobilizing others 3) Ideas and opportunities: spotting opportunities, creativity, vision, valuing ideas, ethical \& sustainable thinking. In a given situation of working life, the relative importance of the multiple elements is not similar, and all competences are not always equally crucial.

This paper discusses the results of the V-Tours study project that was co-funded by the Erasmus+ and run in collaboration with partners from four European countries. The aim was to increase and improve dialogue and understanding between university students and employers. The first challenge was to identify the skills needed for employability in different sectors. The second challenge was to design a virtual space where HEl students can meet employers and take advantage of learning opportunities to develop their employability skills. The third challenge was to co-create content on the virtual space together with the three different key partners: education, employers and students. 


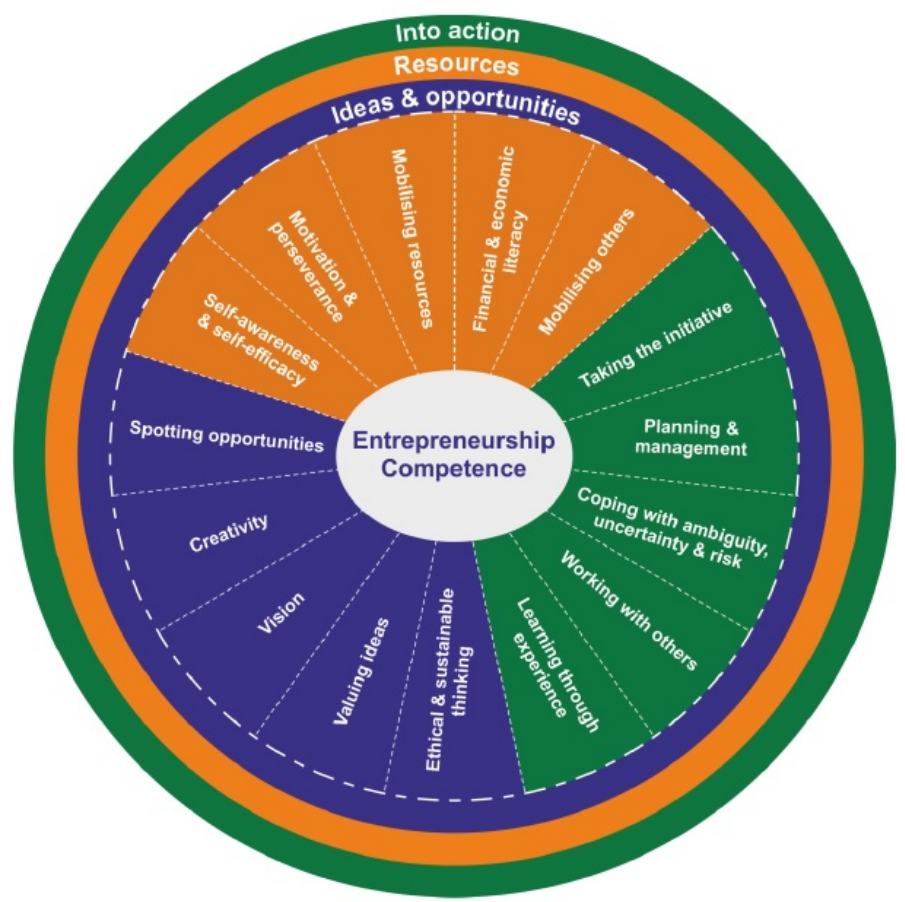

Figure 1: Areas and competences of entrepreneurship, EntreComp conceptual model [6].

\section{METHODOLOGY}

\subsection{Understand}

\subsubsection{Competences and Skills Needed for Employability}

The aim was to identify the employability skills and priorities given by employers. Identification of the skills was based on desk research and field studies. The former was performed with the help of FINNA library research engine on recent (2012-2017) studies related to the key words "employability or working life or entrepreneur or entrepreneurship" and "competences/competencies or skills" and/or "graduates".

Field studies were realized by two Laurea University of Applied Sciences units in Southern Finland. In the first phase, altogether 32 nursing students participated in the work where 19 various types of nurses' employers were studied using the semi-structured interview-method in Spring 2017.

The EntreComp model (Figure 1) [6] served as a theoretical framework. At first, the students familiarized themselves with the subject from the theoretical and practical point of view.

The next step was a dialogue with working life. Semi-structured Interviews were conducted face-toface as this increases both understanding, tone, speech and nonverbal communication and can be interpreted to enhance credibility or suspicion. The language of the discussions was English or Finnish. The themes were the following: a) the five (5) most essential employability competences; $b$ ) frequency of these employability competences among job seekers; c) means of detection in recruitment situations; d) less essential competences; e) future requirements. All interviews were audio-recorded, and most were also audio-video recorded. Interviews were analyzed by lecturers using the structure of EntreComp-model.

The project continued in the fall of 2017 when six business students at Hyvinkää campus conducted 13 interviews. Five of the interviews were face-to-face and eight carried out over the phone. The first ones were filmed and the second ones audio-recorded. The companies chosen for the interviews represented fields in which business students commonly are employed: marketing, gaming industry, entrepreneurship, human resources, well-being, e-commerce, finance sector, metal industry, and public administration. 
The execution of the project was based on a learning model called P2P, short for Peer to Peer. The P2P model was first introduced in business studies in August 2008, at the Hyvinkää campus of Laurea University of Applied Sciences. The objective of the P2P model is to combine studies and theoretical knowledge within the business world. Today all business studies at the Hyvinkää unit are carried out in work-life projects. Project groups usually consist of 5-6 students and their work is supervised by two senior lecturers, and during the project, which usually lasts for one semester and is eligible for 15 credits, students conduct a work-life project commissioned by a real company.

The implementation of the project followed a structured process chart (Figure 2) First, the group met the client and the assignment was introduced to the students. At the beginning of the project, the students defined their team roles. The team manager had the overall responsibility for the execution of the project. The vice project manager assisted the project manager. To make sure that the all the meetings would be appropriately documented one student was the secretary and another one a vice secretary. All the parties, the client who had commissioned the project, the students and the teachers signed a project agreement. In this case, the client was the V-Tours project, and the representative of the project was a Senior Lecturer at Laurea University of Applied Sciences who was in the Erasmus+ V-Tours team. The students did not only execute the project, in this case, conduct the interviews, but they familiarized themselves with literature linked to the project's theme and wrote a theoretical framework to ensure that they had a comprehensive understanding of the essential concepts of the topic. The project group compiled the interview questions, chose and contacted the companies they found interesting from the project's point of view, they conducted the interviews and edited the filmed interviews. The project group also analyzed the results and wrote a project report. Besides, they organized an online seminar where they introduced the results to the companies that participated in the interviews.

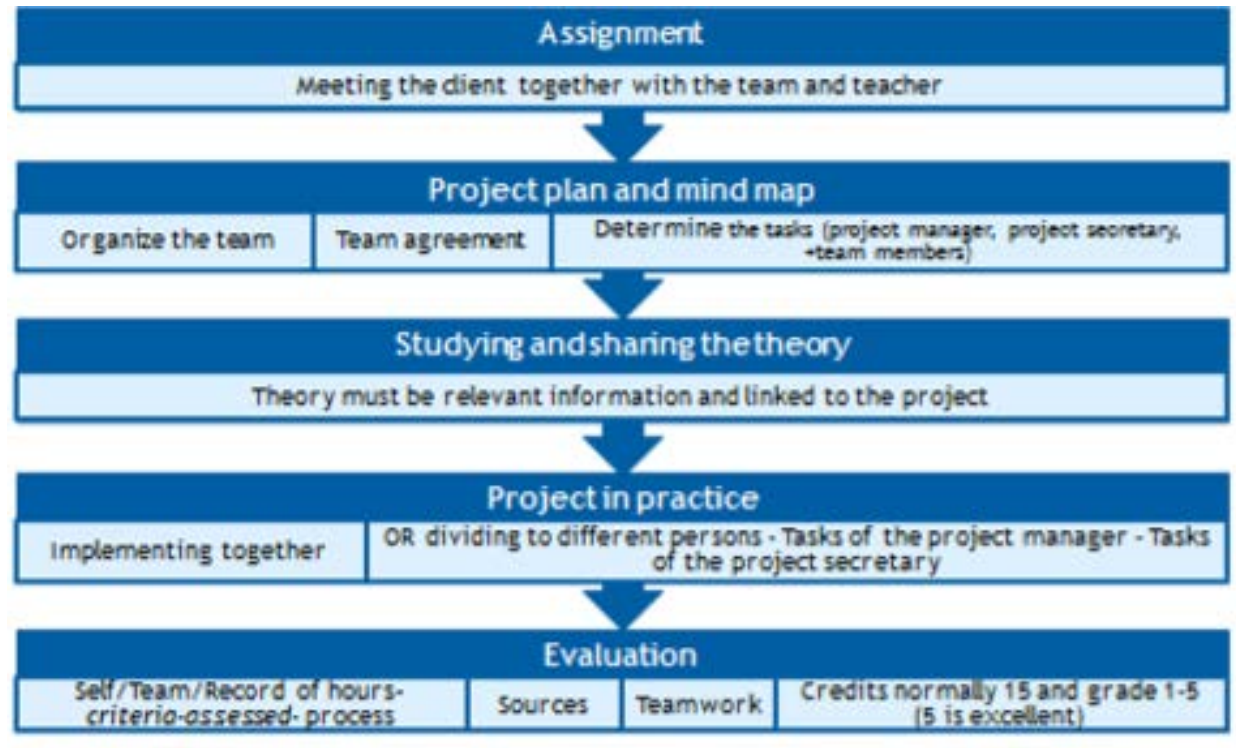

Figure 2: The Learning Process in P2P

\subsubsection{Best Practices}

For further development and design work understanding was also necessary, on the one hand, related to "best practices" on how to foster business culture acquisition among students and, on the other hand, the needs of the enterprises, students, guidance and placement workforce, and stakeholders involved in transition moment between education and the labour market. This information was collected with the help of a special questionnaire developed in the project by all V-Tours project partners - that is in Finland, Italy, Republic of Macedonia and Spain. The project partners also realized in each country desk research to gather local OERs (Open educational resources that are free and openly licensed educational materials that can be used for teaching, learning, research, and other purposes [7] related to the addressed competences acquisition. 


\subsection{Plan}

Planning the design and development step for the final outputs was based on sharing and agreeing with companies on common interests related to transitions from education to work in order to improve the process and give value to both players.

The results of the field research on nursing were shared with local employers in a seminar (Hiiden alueen Hoitotyön kehittäjät) organized in Southern Finland in November 2017 and distributed mainly with the help of a poster presentation at the Finnish Nursing Exhibition 23.-24.4.2017 in Helsinki.

Laurea business students participated in a Nordic Business Forum event organized in Helsinki (Haaga-Helia UAS) in October 2017 for sharing and discussing with business sector employers. Moreover, the results were discussed with the scientific society in international conferences in Spain in November 2017 [8] [9] and in March 2018 [10].

\subsection{Design}

The design process aimed at developing various services for young graduates to promote understanding and help to develop competences needed for employability. Various service innovation methods including co-creative workshops were used with stakeholders locally and transnationally.

\subsubsection{Online course}

The $\mathrm{V}$-Tours project partners designed an online course on business culture and work ethics to contribute to a smooth transition from education to the world of work. An essential objective of the course is to improve students' working life competences.

The course concentrates on positive attitude and initiative, communication and interaction, teamwork and collaboration, critical and analytical thinking, creativity and innovation and perspective to digitalization.

The design of the course focused on creating the contents of the course so that it would support the development of these competences. The project partners introduced four topic areas with selfreflection and self-assessment exercises for students. These are 1) me as an employee, 2) organizational culture, 3) corporate social responsibility and 4) re-thinking approaches to work life.

Laurea's two nursing students were involved in developing a study unit. Moreover, 31 other nursing students participated in beta-testing of the pilot version of the online course in November-December 2017. A special questionnaire was developed for the evaluation of the pilot. After the pilot testing the learning material was developed further together with these students.

In January 2018 the online course material was discussed among the $\mathrm{V}$-Tours partners. A new version of the online course was then created in February 2018 by two partners (Italian and Spanish). This version was tested in Finnish, Italian, Macedonian or Spanish organizations in Spring 2018.

\subsubsection{Other Training Material}

Laurea University of Applied Sciences produced altogether 28 virtual visits to different working environments consisting of private and public organizations. Altogether 37 Laurea students from two campuses were involved in carrying out the planning and production of these videos. The videos were produced from the audio-video recorded interviews, edited and subtitled in English/Finnish depending on the original version.

Six videos present employers' perception of employability requirements in the business sector.

At first, 32 nursing students produced virtual tours of 19 different nurses' working environments. Virtual Tours are audio-recorded videos that describe the nurse's role and employability skills required in the questioned environment. In the videos, it is also described how employers use to identify and to which extent young job applicants are in general capable of demonstrating their employability skills in a recruitment situation. From these 19 original videoed interviews four combined videos were produced on the following themes: of 1) Nurses' working life environment, namely 2) Nurse's employability skills at present, 3) Nurse's employability skills in the future and 4) Identification of employability skills in recruitment situations. 
Nursing students also developed 30 comic strips to visualize the various working life situations where the entrepreneurial competences [6] come into practice and how they influence the outcome of the nursing and caring situations.

\subsubsection{Virtual Tours to Working Life}

In this context virtual tours refer to learning pathways made available for students to enhance their knowledge about the present and future employability skills expected by the employers. In the V-Tours project, this was done by producing synchronous and asynchronous interviews with employers in Finland, FYR of Macedonia, Italy, and Spain. Companies for the virtual tours were selected among business partners in a manner that various tours covered different sectors of the graduates' eventual future employers.

\section{RESULTS}

The final outputs consisted of the following:

1) Creation of deep understanding of the employability skills in various sectors of working life among the project partners and the participating teachers and students.

The five most essential competences for nurses in their order of importance was the following: Working with others (16/19 answers); Mobilizing resources (15/19); Coping with uncertainty, ambiguity, and risk (15/19); Mobilizing others (13/19); Taking the initiative (8/19).

The study in the business sector showed that the most essential employability skills now and in the future are social interaction skills (=Working with others, 12/13), self-management (Taking the initiative, 6/12), language skills (Resources, 5/13), being able to adapt to change (=Coping with uncertainty, ambiguity and risk 5/13), and good IT skills (Resources, 3/13).

All the results were in line with previous research.

2) The $V$-Tours online course on Business Culture brings together a vast amount of information and insights to business culture and gives beneficial guidance to graduating students on how things work in their future workplaces and how to get prepared for their professional career.

3) Virtual tours in business: altogether nine audio-video recorded virtual tours in business culture in Finland, Italy, Republic of Macedonia or Spain.

4) Design and development of other learning material namely 25 videos and 30 cartoon strips on nurses' working life and requirements, five videos on business sector requirements.

5) Understanding of business culture and competences and skills required for employment among students who participated in the project. Altogether 65 Laurea's nursing and six business administration students participated actively in the V-Tours project.

According to a study conducted by Paul Dickinson [11], a Senior Lecturer in Business Management at Laurea University of Applied Sciences, students learn and improve the most crucial employability skills already during their studies through this type of project work. The goal of the P2P model is to build up students' theoretical knowledge and improve their employability skills in a real-life context. Students search for information and apply it in the project. The client actively participates in the process and gives feedback already during the project, and sometimes the project is even carried out on the client's premises. Students have to co-operate with the other members of the project group, the supervising teachers, the client, and other work-life representatives. Having good social interaction skills is an essential skill to implement a project successfully. Furthermore, this type of project work enhances individuality in learning and increases the students' self-directiveness (Dickinson, 2017). Students are responsible for meeting the learning objectives of the project, for communication with the client and executing the project. Dickinson [11] also discusses the important role of technology in P2P projects. Students, teachers, and clients have online meetings; students use different software and applications to write theory, draw charts and diagrams to present the results, and the Internet to search for information. In the interviews, several interviewees highlighted good IT skills. Through project work, students acquire a good command of information technology already during their studies. Besides, students are obligated to participate in two international projects where the language of tuition and communication is English. International exchange students take part in the international projects alongside with Finnish students. All the agendas, memos and reports are written in English. According 
to Dickinson [11], $45 \%$ of the students reported that their English skills, both written, oral and vocabulary, improved during the international projects.

By interviewing the employers on the competences and skills required for employability the students got an insight on what the companies and organizations are expecting when recruiting new employees. The findings are in line with recent studies [6] [11].

6) Understanding of career possibilities: The nursing students created deep insight into their career possibilities in public, private and third sector and in the future changing working life. The students got knowledge that they can make their own study choices according to their career path and on the other hand they must take responsibility for their choices as a student [8].

7) Discovering employers' needs related to recruitment situations: Results of the interviews were also discussed with representatives of working life regionally, nationally and internationally. Identifying and demonstrating future employability skills were considered necessary but often difficult in working life and recruitment. It was considered essential to develop tools that suit traditional recruitment interview situations to identify the required competences. One employer pointed out that they find useful the comic strips produced in the V-Tours project for identifying e.g., ethical awareness of the job candidate in the recruitment situation [8].

8) Revealing educational needs: The importance of supporting the students' employability skills in education became clear to all researchers and lecturers who participated in the project. Teachers should offer possibilities for the students to learn about working life opportunities and career possibilities. At the same time, it is vital to help students to identify their competences and skills and the ones needed for employment. Therefore, these abilities need to be observable and measurable. Practical tools like the videos and comic strips can help create links between education and working life. However, teachers need to keep continuous contact with the working world to ensure that education developed in the appropriate manner and that teachers are aware of the future requirements and trends or work-life.

8) Revealing the roles: The study revealed [9] that to succeed in answering to the changing requirements of working-life, business and universities should share the responsibility and create awareness on both sides of the complexities of the other. Higher education should act as a facilitator of learning in the collaboration where all partners, education, business and learners, assure their active role and responsibilities. This partnership should be developed in a way that the various needs are developed and the ways of answering them is realised as a joint venture where all partners identify their role.

Business should identify their own needs and make them visible and understandable. In this transfer one practical way can be development of offering of internships and job placements where students can be designed real challenges and responsibilities which, if possible also vary during the length of the collaboration.

The promotion of digital learning together with development and use of flexible digital learning and teaching methods enable appropriate integration of different business partners in the learning process on local, national, international or even global level.

Through the transitions, also the students' role changes. They become responsible for learning, participate in determination of learning goals and hold an active role in the learning as well as in evaluating their learning outcomes. When holding an active role in the learning process, students can practice extrapolation and transfer of knowledge. In the modern "triple helix model" of education business and learners, teachers have the role of facilitators of learning offering the means to building the content and choosing the methods. Content is used to build a knowledge base and to develop learning skills and learner's self-awareness [8][9][10].

\section{CONCLUSIONS}

Several studies have proved the importance of transversal skill. Recently employability competences have been summarised in the concept of Entrepreneurial skills (EntreComp conceptual model). The field studies presented in this paper are in line with the model and reveal how the importance of different sub-skills vary in different fields of working life.

Continuous dialogue between working world, education and learners is necessary for assuring mutual understanding and. Employers learn to present their job requirements more distinctly and underline 
the required competences. Job seekers learn to take responsibility for identifying and developing the competences and skills required to match the career path they wish to tackle. Recruitment should be developed to better reveal the existing competences.

The intercultural Erasmus+ co-funded V-Tours project presented in this paper reveals many possibilities for developing education in the sense that it offers students deep insights into working world requirements. This project has been very beneficial in many ways and has had strong impact on the participating people and organizations.

\section{ACKNOWLEDGEMENTS}

This study was supported by the European Commission, Erasmus Plus program - Cooperation for innovation and the exchange of good practices, Strategic Partnerships for higher education, activity KA2, project no: 2016-1-IT02-KA203-024195. This paper reflects the views only of the authors and the Commission cannot be held responsible for any use which may be made of the information contained therein.

\section{REFERENCES}

[1] OECD. Skills for Innovation and Research, OECD Publishing, 2011. Available at: http://dx.doi. org/10.1787/9789264097490-en

[2] Esposto, A. Skill: An Elusive and Ambiguous Concept in Labour Market Studies. Australian Bulletin of Labour 34(1), pp. 100-124, 2008.

[3] Rychen, D. S. \& Salganik, L. H. Definition and Selection of Key Competencies: Theoretical and Conceptual Foundations. INES GENERAL ASSEMBLY 2000. Available at: http://www.deseco.admin.ch/bfs/deseco/en/index/02.parsys.69356. downloadList.26477.DownloadFile. tmp/2000.desecocontrib.inesg.a.pdf

[4] Boyatzis, R.E. Competencies in the 21st century. Journal of Management Development 27(1), pp. 5-12, 2008.

[5] Spencer, L. \& Spencer, S. Competence at Work: Models for Superior Performance, New York: John Wiley \& Sons, 1993.

[6] Bacigalupo, M., Kampylis, P., Punie, Y. \& Van den Brande, G. EntreComp: The Entrepreneurship Competence Framework. Luxembourg: Publication Office of the European Union, 2016.

[7] William \& Flora Hewlett Foundation. Open Educational Resources. https://hewlett.org/strategy/open-educational-resources/

[8] Sievers, A., Ranta, L. \& Guilland, A. Creating Insight Among Students on Working Life Competences Through Problem Based Learning. In L. Gómez Chova, A. López Martínez \& I. Candel Torres (eds.) ICERI2017 Conference Proceedings. 10th annual International Conference of Education, Research and Innovation, pp: 713-721, Seville, Spain, 16-18 November, 2017. ISBN: 978-84-697-6957-7, ISSN: 2340-1095. IATED Academy, Spain. doi: 10.21125/iceri.2017.0266

[9] Ranta, L., Sievers, A. \& Guilland, A. Shared Responsibility of Higher Education Institutes (HEI) and Their Partners in Assuring Nursing Students' Employability Skills. In L. Gómez Chova, A. López Martínez \& I. Candel Torres (eds.) ICERI2017 Conference Proceedings. 10th annual International Conference of Education, Research and Innovation, pp: 1247-1255. IATED Academy, Spain, Seville, Spain, 16-18 November, 2017. doi: 10.21125/iceri.2017.0412, ISBN: 978-84-697-6957-7, ISSN: 2340-1095.

[10] Guilland, A. Considerations for solving the skills mismatch of young graduates and requirements of Business World. Proceedings of INTED2018 Conference 5th-7t, pp. 2252-2259, Valencia, Spain, March 2018. ISBN: 978-84-697-9480-7

[11] Dickinson P., (2017). P2P Educational Model Providing Innovative Learning by Linking Technology, Business and Research. Universal Journal of Educational Research, 5(10), p. 1748-1758, Horizon Research Publishing. doi:10.13189/ujer.2017.051012 